\title{
Study of Electrolyte Profile Levels in Hypoglycemic Diabetic Mellitus in Tertiary Care Hospital
}

\author{
Prabha Verma ${ }^{1}$, Sadhana Verma ${ }^{2}$, Sapna Jaiswal ${ }^{3}$ \\ ${ }^{1}$ Assistant Professor, Department of Biochemistry, M.L.B. Medical College, Jhansi, ${ }^{2}$ Assistant Professor, Department of Biochemistry, LPS Institute of Cardiology, \\ GSVM Medical College, Kanpur, ${ }^{3}$ Tutor, Department of Biochemistry, Dr. Ram ManoharLohia Institute of Medical Sciences, Lucknow.
}

\section{Abstract}

Background: Diabetes mellitus (DM) is usually referred as diabetes. It is a group of metabolic disorders in which there are high blood sugar levels over a long period. The main symptoms of high blood sugar are frequent urination, increased thirst, and increased hunger. Subjects and Methods: This cases control study was conducted in the Department of biochemistry in a medical college. This case control study had two groups. Each group contains 30 populations. The duration of study was over a period of six month. Results: In our study 60 total number populations were included. Total populations were divided in two group one in study group and another one control group. In the study group male were dominant followed by female. Conclusion: This study concludes that, the prevalence of Type II diabetes mellitus is increasing day by day and is associated with a very high mortality rate, reduced quality of life and high costs of treatment, despite intensive insulin treatment.HbA1c can be used as early detector of diabetic complications and hypoglycemia in addition to glycemic control. Electrolyte profile and magnesium level estimation will allow the identification of patients with diabetic complications at very early course of the disease.

Keywords: Hypoglycemia, Diabetes Mellitus.

Corresponding Author: Dr. Sadhana Verma, Assistant Professor, Department of Biochemistry, LPS Institute of Cardiology, GSVM Medical College, Kanpur.

Received: August 2019

Accepted: August 2019

\section{Introduction}

Diabetes mellitus (DM) is usually referred as diabetes. It is a group of metabolic disorders in which there are high blood sugar levels over a long period. The main symptoms of high blood sugar are frequent urination, increased thirst, and increased hunger. ${ }^{[1-2]}$ Diabetes can cause many problems,if left untreated. ${ }^{[2]}$ It can caused diabetic ketoacidosis, hyperosmolar hyperglycemic state, or death. ${ }^{[3]}$ it can create some serious prolonged complications also such as cardiovascular disease, stroke, chronic kidney disease, foot ulcers, and damage to the eyes. ${ }^{[2]}$ The reason behind diabetes is due to either the pancreas not producing enough insulin or the cells of the body not responding properly to the insulin produced. There are mainly three types of diabetes mellitus. ${ }^{[2]}$ Type $1 \mathrm{DM}$ results from the pancreas's failure to produce enough insulin. Previously, it was referred to as "insulin-dependent diabetes mellitus" (IDDM). Type 2 DM starts with insulin resistance, in which cells fail to respond to insulin properly. It was previously referred to as "non-insulin-dependent diabetes mellitus" (NIDDM) or "adult-onset diabetes". It is mainly caused due to the excessive body weight and not enough exercise. Gestational diabetes is the third type of DM. it arises when pregnant women without a previous history of diabetes develop high blood sugar levels. ${ }^{[2]}$ For prevention, it is important to maintain a healthy diet, regular physical exercise, a normal body weight, and avoiding use of tobacco. Type 1 DM must be treated with insulin injections. ${ }^{[2]}$ Type 2 DM may be cured with medications. Gestational diabetes generally resolves after the birth of the baby. Glycosylated hemoglobin (HbAlc) is the most vital target of glycemic control. For HbA1c, the desirable value is below 7.00. It indicates the average blood glucose during the past three months which is essential to ensure the optimal care of diabetic patients. It has been revealed by researches that one percent reduction in the value ofHbA1c reduced the risk of micro vascular complications by40 percent. Electrolytes are present in the human body. Electrolytes play an important role in controlling fluid levels, acid-base balance $(\mathrm{pH})$, nerve conduction, and blood clotting and muscle contraction. Potassium, sodium and calcium are all responsible for proper electrolyte balance. Kidney failure, dehydration, fever, and vomiting can lead to electrolyte imbalance and further can create complications in diabetes and other endocrine disorders. The osmotic effect of glucose caused decrease in circulating blood volume and fluid shift from the intracellular spaces causing cellular dehydration. ${ }^{[4-5]}$ The present study aims to identify the relationship of serum electrolytes with fasting blood 
glucose levels in diabetic subjects.

\section{Subjects and Methods}

\section{Study Area}

This cases control study was conducted in the Department of biochemistry in...........medical college.

\section{Study Population}

This case control study had two groups. Each group contains 30 populations.

\section{Study Duration}

The duration of study was over a period of six month.

\section{Data Collection}

30 study group with type II DM with hypoglycemia (blood glucose level $<70 \mathrm{mg} / \mathrm{dl}$ ) who attended theoutpatient clinic of the Medicine Department and 30 age, sex matched healthy controls. All patients with known history of type II DM within the age group of 35-70 years included in the study. Information about subject's age, sex, lifestyle, family history of diabetes and other chronic diseases/disorders were written in pre-design format. HbA1c assay was done by immunoassay method, fasting blood glucose by GOD/POD method, Sodium by Sodium Calib. Set Barcode Levels, Potassium by Potassium Calib. Set Barcode Levels and Magnesium by Xylidyl Blue colorimetric method - all measured by Randoxautoanalyzeron the same day of collection.

\section{Sample Collection}

$3 \mathrm{~mL}$ blood sample was collected from each subject. Fasting,bloodsample in sterile fluoride bulb for FBS,plain bulb for sodium, potassium, magnesium and in EDTA bulb for $\mathrm{HbA1c}$ under all the aseptic conditions with consent of the patient. Blood Sample was allowed to stand for clotting for 25 to 30 minutes. Serum was separated by centrifuging blood at 3000rpm for 10 mins.

\section{Inclusion Criteria}

All patient with known history of type II DM, age group between 35-70 years blood glucose level $<70 \mathrm{mg} / \mathrm{dl}$ and diabetic patients, those whogave the consent for the study were included in the study.

\section{Exclusion Criteria}

Patient with major illness like liver disease, renal failure, cardiovascular disease, which can directly or indirectly affect the result, previous or current treatment with drugs known to interfere with glucose and lipid metabolism were excluded from the study.

\section{Data Analysis}

Data were analyzed by using Microsoft excel.

\section{Results}

In our study 60 total number populations were included.
Total populations were divided in two group one in study group and another one control group. In the study group male were dominant followed by female.We found that in this study 16 cases belonged to 51-60 age group followed by other age group whereas; in the control group 15 cases were found from 51-60 age groups. Study of electrolyte profile levels in hypoglycemic diabetic mellituswere showing in table number 3 .

\begin{tabular}{l}
\hline Table 1: Distribution of Cases According To Gender. \\
\begin{tabular}{|c|c|c|c|}
\hline $\begin{array}{l}\text { No of } \\
\text { cases }\end{array}$ & $\begin{array}{l}\text { Involvement of } \\
\text { left ovary } \quad(\%)\end{array}$ & $\begin{array}{l}\text { Involvement of } \\
\text { right ovary (\%) }\end{array}$ & $\begin{array}{l}\text { Involvement of } \\
\text { both ovaries (\%) }\end{array}$ \\
\hline 100 & $32(\%)$ & $28(\%)$ & $40(\%)$ \\
\hline
\end{tabular}
\end{tabular}

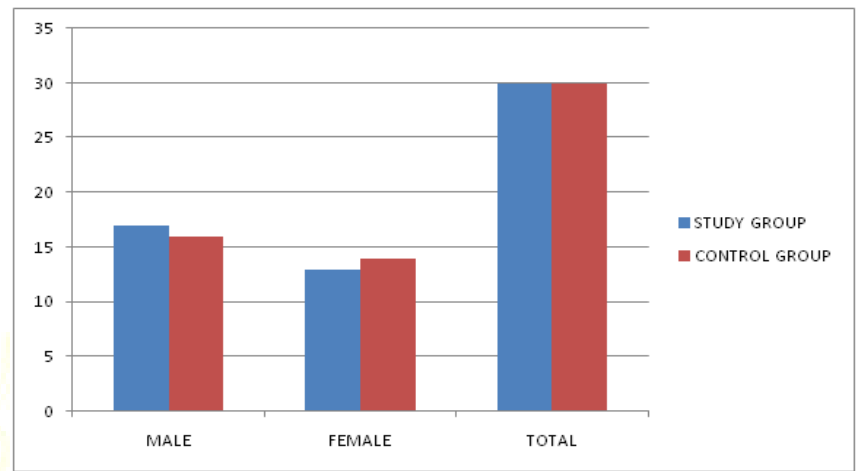

Chart 1: Distribution of Cases According To Gender

Table 2: Distribution of Cases According To Age

\begin{tabular}{|l|l|l|}
\hline Age & Study Group & Control Group \\
\hline $35-40$ & 4 & 3 \\
\hline $41-50$ & 2 & 5 \\
\hline $51-60$ & 16 & 15 \\
\hline $61-70$ & 8 & 7 \\
\hline Total & 30 & 30 \\
\hline
\end{tabular}

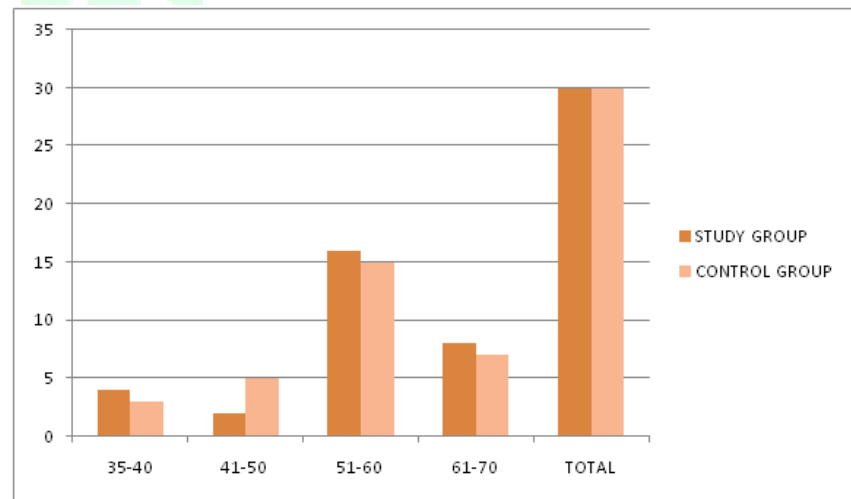

Chart 2: Distribution of Cases According To Age

Table 3: Comparision Study of Electrolyte Profile Levels in Hypoglycemic Diabetic Mellitus\& Healthy Population

\begin{tabular}{|l|l|l|l|l|l|}
\hline \multirow{2}{*}{ Parameters } & \multicolumn{2}{|l|}{$\begin{array}{l}\text { Study Group } \\
(\mathbf{3 0})\end{array}$} & \multicolumn{2}{l|}{$\begin{array}{l}\text { Control group } \\
(\mathbf{3 0})\end{array}$} & P value \\
\cline { 2 - 6 } & Mean & SD & Mean & SD & $\mathbf{0 . 0 0 0 1}$ \\
\hline HbA1c & 6.94 & 0.47 & 5.39 & 0.23 & 0.0001 \\
\hline FBS & 61.43 & 2.84 & 0.52 & 36.27 & 0.0001 \\
\hline $\begin{array}{l}\text { Magnes } \\
\text { ium }\end{array}$ & 1.06 & 0.25 & 0.04 & 0.16 & 0.0001 \\
\hline $\mathrm{Na}+$ & 128.26 & 2.46 & 0.44 & 3.15 & 0.0001 \\
\hline $\mathrm{K}+$ & 6.09 & 4.03 & 0.04 & 0.07 & 0.0001 \\
\hline
\end{tabular}




\section{Discussion}

This study evaluated the risk factors of hypoglycemia in Type II Diabetic Subjects. The findings of the study showed that $\mathrm{HbA1c}$ was significantly higher in the cases in comparison to controls $(\mathrm{p}<0.0001)$. Elevated HbA1c considered as a very high risk for diabetic patients and leads to severe complications. Whereas improvedglycemic control can reduce the risk of various complications in diabetic subjects.[6] Diabetes Complications and Control Trial (DCCT) stated that HbAlc is the best standard of glycemic control and $\mathrm{HbA} 1 \mathrm{c}$ value $\leq 7.0 \%$ is the level of significance for reducing diabetic complications. ${ }^{[7]}$ Previously Khaw et al conducted a study and showed that by reducing the level of glycated hemoglobin $(\mathrm{HbA} 1 \mathrm{c})$ by $0.2 \%$ could lower the mortality rate by $10 \% \cdot{ }^{[8]}$ In non-diabetic individuals, $\mathrm{HbA} 1 \mathrm{c}$ reflects average blood glucose concentration over the course of the $\mathrm{RBC}$ lifespan. HbA1c is the most widely used biomarker for long-term glycemic status. ${ }^{[9]}$

The present study found a significant lower sodium values in the cases $(\mathrm{p}<0.0001)$. the reason could be due to the hyperglycemia increases serum osmolality which leads to movement of water out of the cells and subsequently in a reduction of serum sodium levels $[\mathrm{Na}+]$ by dilution. Furthermore, in diabetic ketoacidosis ketone bodies (bhydroxybutyrate and acetoacetate) obligate urinary electrolyte losses and aggravate therenal sodium wasting. ${ }^{[10,11]}$ Drug-induced hyponatremia due to hypoglycemic agents or other medications (e.g., diuretics, amitriptyline) should be considered in every diabetic patient with low $[\mathrm{Na}+]^{[12,13]}$ this study also observed a significant higher level of potassium $(\mathrm{p}<0.0001)$. The main cause of Hyperkalemia might be due to redistribution of potassium from the intracellular to the extracellular compartment. It reduced glomerular filtration of $\mathrm{K}+$ due to acute kidney injury and chronic kidney disease;several drugs that interfere with $\mathrm{K}+$ excretion are related with hyperkalemia. Healthy diabetic diet is often rich in $\mathrm{K}+$ and low in sodium contributing to the occurrence of hyperkalemia in susceptible individuals. ${ }^{[14,15,16]}$

Our study found that there are significant lower serum magnesium levelsin the cases in comparison to controls. Similar results were found in the study of Nadler et al. ${ }^{[17]}$ Results also revealed thatprolonged use and the improper dosing of insulin leads to hypoglycemia in the type II diabetic patients.

\section{Conclusion}

This study suggested that, the prevalence of Type II diabetes mellitus is increasing day by dayand is associated with a very high mortality rate, reduced quality of life and high costs of treatment, despite intensive insulin treatment.HbA1c can be used as early detector of diabetic complications and hypoglycemia in addition to glycemic control. Electrolyte profile and magnesium level estimation will allow the identification of patientswith diabetic complications at very early course of the disease. Risk factor modification, $\mathrm{HbA1c}$, magnesium levels and electrolyte profile monitoring and combined therapies are the current integrated approaches to manage the diabetic complications like electrolyte imbalance, hypomagnesaemia, nephropathy in patients with hypoglycemic Type II diabetes

\section{References}

1. Diabetes Blue Circle Symbol. International Diabetes Federation.Archived from the original, 2006, 2007.

2. Diabetes Fact sheet $N^{\circ} 312$. WHO.October.Archived from the original on 26 August 2013.Retrieved, 2013, 2014.

3. The top 10 causes of death Fact sheet $\mathrm{N}^{\circ} 310$. World Health Organization. Oct 2013. Archived from the original, 2017.

4. About diabetes World Health Organization. Archived from the original on 31 March 2014.Retrieved, 2014.

5. Shoback, edited by David G. Gardner, Dolores. Chapter 17. Greenspan's basic \& clinical endocrinology (9th ed.). New York: McGraw-Hill Medical, 2011. ISBN 0-07- 162243-8.

6. Selvin E, Wattanakit K, Steffes MW, et al. HbA1c and peripheral arterial disease in diabetes: the atherosclerosis risk in communities study. Diabetes Care 2006;29(4):877-882.

7. Rohlfing CL, Wiedmeyer HM, Little RR, et al. Defining the relationship between plasma glucose and HbA1c: analysis of glucose profiles and $\mathrm{HbA} 1 \mathrm{c}$ in the diabetes control and complications trial. Diabetes Care 2002;25(2):275-278.

8. Khaw KT, Wareham N, Luben R, et al. Glycated hemoglobin, diabetes and mortality in men in Norfolk cohort of European prospective investigation of cancer and nutrition (EPIC Norfolk). BMJ 2001;322(7277):15- 18.

9. 9. Selvin E, Coresh J, Shahar E et al (2005) Glycaemia (HbA1c) and incident of ischemic stroke: the Atherosclerosis Risk in Communties (ARIC) Study. Lancet Neurol 4:821-826.

10. 10. Liamis G, Milionis HJ, Elisaf M. Hyponatremia in patients with infectious diseases. J Infect 2011; 63: 327-335 [PMID:21835196 DOI: 10.1016/j.jinf.2011.07.013].

11. Chiasson JL, Aris-Jilwan N, Bélanger R, Bertrand S, Beauregard H, Ekoé JM, Fournier H, Havrankova J. Diagnosis and treatment of diabetic ketoacidosis and the hyperglycemic hyperosmolar state. CMAJ 2003; 168: 859-866 [PMID: 12668546].

12. Liamis G, Milionis H, Elisaf M. A review of drug-induced hyponatremia. Am J Kidney Dis 2008; 52: 144-153 [PMID:18468754 DOI: 10.1053/j.ajkd.2008.03.004].

13. Beukhof CM, Hoorn EJ, Lindemans J, Zietse R. Novel risk factors for hospital-acquired hyponatraemia: a matched casecontrol study. ClinEndocrinol (Oxf) 2007; 66: 367-372.[PMID:17302870 DOI: 10.1111/j.1365-2265.2007.02741.x].

14. Palmer BF. Managing hyperkalemia caused by inhibitors of the renin-angiotensinaldosterone system. N Engl J Med 2004; 351: 585 592 [PMID: 15295051 DOI: 10.1056/NEJMra035279]

15. Uribarri J, Oh MS, Carroll HJ. Hyperkalemia in diabetes mellitus. J Diabet Complications 1990; 4: 3-7 [PMID: 2141843].

16. DeFronzo RA. Hyperkalemia and hyporeninemichypoaldo steronism. Kidney Int 1980; 17: 118-134 [PMID: 6990088].

17. Lal J, Vasudev K, Kela AK, Jain SK. Effect of oral magnesium supplementation on lipid profile and blood glucose of patients with type II diabetes mellitus. JAPI. 2003;51:37-42. 
Copyright: () the author(s), 2019. It is an open-access article distributed under the terms of the Creative Commons Attribution License (CC BY 4.0), which permits authors to retain ownership of the copyright for their content, and allow anyone to download, reuse, reprint, modify, distribute and/or copy the content as long as the original authors and source are cited.

How to cite this article: Verma P, Verma S, Jaiswal S. Study of Electrolyte Profile Levels in Hypoglycemic Diabetic Mellitus in Tertiary Care Hospital. Asian J. Med. Res. 2019; 8(3):BC05-BC08.

DOI: dx.doi.org/10.21276/ajmr.2019.8.3.BC2

Source of Support: Nil, Conflict of Interest: None declared. 